Check for updates

Cite this: RSC Adv., 2017, 7, 47726

Received 30th August 2017

Accepted 3rd October 2017

DOI: 10.1039/c7ra09650j

rsc.li/rsc-advances

\title{
A Raman spectro-microscopic investigation of ETFE-based radiation-grafted anion-exchange membranes $\dagger$
}

\author{
Wai Hin Lee, Carol Crean, (D) John R. Varcoe (D) and Rachida Bance-Soualhi (D) *
}

This study used Raman spectro-microscopy to investigate the synthesis and degradation of radiationgrafted anion-exchange membranes (RG-AEM) made using $50 \mu \mathrm{m}$ thick poly(ethylene-cotetrafluoroethylene) (ETFE) films, vinylbenzyl chloride (VBC) monomer, and 1-methylpyrrolidine (MPY) amination agent. The data obtained confirmed the operation of the grafting-front mechanism. VBC grafting times of 1 and $4 \mathrm{~h}$ led to low degrees of grafting homogeneity, while $72 \mathrm{~h}$ led to extreme levels of grafting that resulted in mechanically weak RG-AEMs due to the excessive $\mathrm{H}_{2} \mathrm{O}$ contents. A grafting time of $16 \mathrm{~h}$ was optimal yielding a RG-AEM with an ion-exchange capacity (IEC) of $2.06 \pm$ $0.02 \mathrm{mmol} \mathrm{g}^{-1}(n=3)$. An excess of grafting was detected at the surface of this RG-AEM (at least within the first few $\mu \mathrm{m}$ of the surface). This RG-AEM was then degraded in $\mathrm{O}_{2}$-purged aqueous $\mathrm{KOH}$ $\left(1.0 \mathrm{~mol} \mathrm{dm}^{-3}\right)$ for $14 \mathrm{~d}$ at $80{ }^{\circ} \mathrm{C}$. Degradation was detected throughout the RG-AEM cross-section, where the Raman data was quantitatively consistent with the loss of IEC. A slight excess of degradation was detected at the surface of the RG-AEM. Degradation involved the loss of whole benzyl-1methypyrrolidinium grafted units as well as the direct attack on the pendent (cationic) pyrrolidinium groups by the hydroxide anions.

\section{Introduction}

Radiation-grafting is a useful technique for the production of functional membranes (and other polymeric materials). ${ }^{1}$ This technique has been commonly used to produce solid electrolytes, e.g. ion-exchange membranes (IEM), including proton-exchange membranes (PEM) for use in technologies such as protonexchange membrane fuel cells (PEMFCs) and PEM-based water electrolysers. ${ }^{2}$ A more recent line of research is the development of anion-exchange membranes (AEM) for use in alkaline AnionExchange Membrane Fuel Cells (AEMFCs) and AEM-based Alkaline Water Electrolysers (AEM-AWE): ${ }^{3}$ this includes the use of radiation-grafted (RG) types. ${ }^{4}$ The use of high $\mathrm{pH}$, hydroxideconducting solid electrolytes allows for a broader range of electrocatalysts that do not involve scarce, expensive Pt. ${ }^{5}$ Scheme 1 outlines the steps involved in the synthesis of such a RG-AEM: pre-irradiation in air (peroxidation) of poly(ethylene-co-tetrafluoroethylene) (ETFE) precursor film, followed by grafting with vinylbenzyl chloride (VBC) monomer and amination with 1-methylpyrrolidine (MPY). ${ }^{6}$

Incomplete grafting can lead to RG-IEMs with lower than ideal functionalisation, which are then too ionically resistive for

Department of Chemistry, The University of Surrey, Guildford, GU2 7XH, UK. E-mail: r. bance-soualhi@surrey.ac.uk

$\dagger$ Electronic supplementary information (ESI) available: Additional data and Raman spectra/maps in support of the main article. See DOI: $10.1039 / \mathrm{c} 7 \mathrm{ra09650j}$ application. Radiation-grafting often involves the grafting-front mechanism, especially with thicker precursor films: ${ }^{6-8}$ this is where grafting initiates on the surfaces of the precursor films

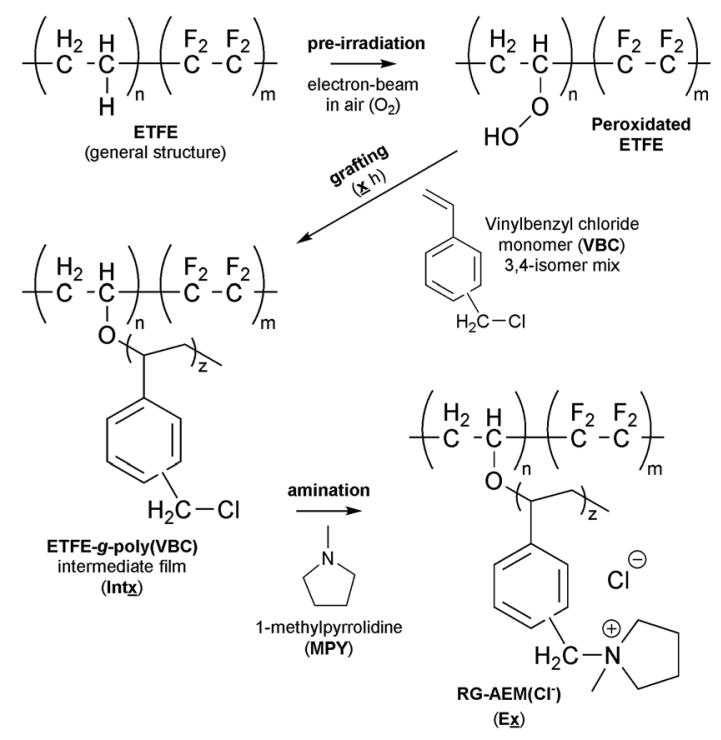

Scheme 1 An outline of the synthesis of ETFE-based pyrrolidiniumtype radiation-grafted anion-exchange membranes (RG-AEM) in the chloride-anion form. The precursor ETFE film used in this study was $50 \mu \mathrm{m}$ thick. The main variable in this study was the grafting time $(x)$. 


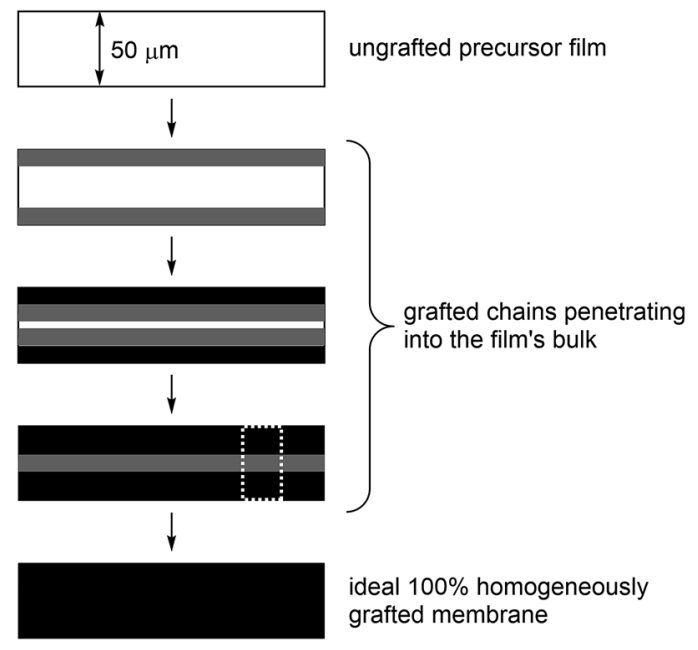

Fig. 1 A diagram showing the grafting front mechanism that is commonly encountered in the synthesis of radiation-grafted membranes. The white dashed rectangle indicates a typical Raman spectro-microscopy cross-sectional mapping region (i.e. the $30 \times$ $65 \mu \mathrm{m}$ areas used in this study).

with the gradual penetration of the grafts into the bulk of the films (Fig. 1). As radiation-grafting involves the modification of solid polymer films (up to $150 \mu \mathrm{m}$ thickness in the literature), ${ }^{1}$ it is essential to assess the uniformity of the monomer grafting (and any subsequent functionalisation) throughout the core of the resulting RG-IEMs. ${ }^{9}$ Techniques that have been used to study the uniformity of grafting include Scanning Electron Microscopy coupled with Energy-Dispersive X-ray Spectroscopy $\left(\right.$ SEM-EDX) ${ }^{8,10}$ and Raman spectro-microscopy. ${ }^{6,9,11}$

Raman spectroscopy can achieve spectral resolutions down to $c a .0 .3 \mathrm{~cm}^{-1}$ and is a powerful spectroscopy that both complements and supports other spectroscopies (vibrational, rotational, and electronic). ${ }^{12}$ As Raman spectrometers involve the use of lasers, the spectrometers are commonly coupled to (confocal) microscopic equipment that allows individual spectra to be recorded on different parts of a sample with spatial resolutions as low as $c a .1 \mu \mathrm{m}$ diameter. ${ }^{13} \$$ As the cost of Raman instrumentation has generally decreased in the last 10 years§ and the familiarity with the technique has increased, the use of Raman spectro-microscopy is becoming more widespread and routine in the field of materials science. The use of Raman spectro-microscopy often has the advantage of requiring minimal levels of sample preparation. The primary disadvantage is that the quality of spectra is often degraded due to the presence of photoluminescence interferences such as fluorescence. If Raman equipment is available that possesses multiple laser wavelengths $(\lambda)$, it is often possible to select a laser

\footnotetext{
\$ Sub-micron resolution can be less routinely obtained with the use of high cost equipment and low wavelength lasers, especially with the use of tip-enhanced Raman spectroscopy (TERS), which couples atomic force microscopes with Raman instrumentation.

$\S$ Raman microscopes are still generally more expensive than for IR instrumentation $(>£ 100 \mathrm{k} v s$. $<£ 50 \mathrm{k})$.
}

wavelength that minimises such interferences (but, obviously, this adds to the cost of the equipment).

Given the spatial resolution of Raman spectro-microscopy can be as low as $1 \mu \mathrm{m}$ during routine measurements (and that previous RG-IEMs reported in the literature are typically up to ca. $150 \mu \mathrm{m}$ in thickness), ${ }^{1}$ this technique can be a useful quality assurance tool for the study of the radiation-grafting homogeneity (especially through the membrane cross-section). Raman spectro-microscopic mapping has already been used to study RG-AEMs, but these experiments have typically taken $8-16 \mathrm{~h}$ per map (as Raman scattered light is of low intensity): ${ }^{6,9}$ this is nonideal considering the life-times of expensive $(£ 10 \mathrm{k}+)$ lasers is typically only a few thousand hours (of in use time).

Herein, the aim of this study is to investigate the optimum laser wavelength and spectral collection parameters that will allow for the more rapid and routine use of Raman spectromicroscopy in the study of each stage (grafting, amination) of the synthesis of RG-AEMs. This study will then use this knowledge to conduct an initial investigation into the homogeneity of the degradation of a RG-AEM when it is exposed to aqueous $\mathrm{KOH}\left(1.0 \mathrm{~mol} \mathrm{dm}^{-3}\right)$ at $80{ }^{\circ} \mathrm{C}$ for $14 \mathrm{~d}$.

\section{Experimental}

\section{Materials and chemicals}

Commercial Nowoflon ET-6235Z ETFE film of $50 \mu \mathrm{m}$ thickness was supplied by Nowofol Kunstoffprodukte GmbH (Germany) and was used as the precursor material. Vinylbenzyl chloride (VBC, 97\%, mixture of 3- and 4-isomers, used without removal of 4-tert-butylcatechol and nitromethane inhibitors), 1-octy-2pyrrolidone dispersant, and 1-methylpyrrolidine (MPY, 97\%) were purchased from Sigma-Aldrich. Standardised analytical aqueous solutions of $\mathrm{AgNO}_{3}\left(20.00 \pm 0.06 \mathrm{mmol} \mathrm{dm}^{-3}\right)$ and aqueous $\mathrm{HNO}_{3}\left(2.0 \mathrm{~mol} \mathrm{dm}^{-3}\right)$, used for the IEC determinations, were supplied from Fluka. All other chemicals, including analytical grade aqueous solutions of $\mathrm{NaCl}\left(1.0 \mathrm{~mol} \mathrm{dm}^{-3}\right)$ and $\mathrm{KOH}\left(1.0 \mathrm{~mol} \mathrm{dm}{ }^{-3}\right)$, toluene, and $\mathrm{NaNO}_{3}(\mathrm{~s})$ were used as received. Ultrapure water (UPW, resistivity $=18.2 \mathrm{M} \Omega \mathrm{cm}$ ) was used throughout this study.

\section{Preparation of the radiation-grafted anion-exchange membranes}

Grafting stage. The pre-aminated ETFE-g-poly(VBC) membranes were prepared by grafting VBC onto peroxidated ETFE films as described previously. ${ }^{9}$ The ETFE films $(13 \times$ $13 \mathrm{~cm}$ ) were irradiated in air to $70 \mathrm{kGy}$ total absorbed dose using a 4.5 MeV Dynamatron Continuous DC Electron Beam Unit (Synergy Health, South Marston, UK, see Fig. S1 in the in the ESI $\dagger$ ). The peroxidated films were immersed into glass tubes containing a mixture $\left(250 \mathrm{~cm}^{3}\right)$ of $5 \%$ vol. VBC, $1 \%$ vol. 1-octy-2pyrrolidone, and $94 \%$ vol. UPW, which was then purged with $\mathrm{N}_{2}$ for $2 \mathrm{~h}$. The sealed tubes were subsequently placed in a preheated water bath at $70{ }^{\circ} \mathrm{C}$ for the desired duration of grafting reaction (1-72 h). Finally, the grafted membranes were thoroughly washed with toluene and then dried in a vacuum oven at 
$70{ }^{\circ} \mathrm{C}$. The degree of grafting (DoG) of each pre-aminated membrane was calculated as follows:

$$
\operatorname{DoG}(\%)=\frac{m_{\mathrm{g}}-m_{\mathrm{i}}}{m_{\mathrm{i}}} \times 100
$$

where $m_{\mathrm{g}}$ is the mass of the grafted membrane and $m_{\mathrm{i}}$ is the initial mass of the peroxidated ETFE film used.

Amination stage. A previous study revealed that amination with MPY yielded RG-AEMs that were more stable towards attack by $\mathrm{OH}^{-}$anions (more alkali stable) than RG-AEMs synthesised using the more commonly encountered trimethylamine (TMA) reagent. ${ }^{6}$ Therefore, MPY was used to convert the pre-aminated membranes into the desired RG-AEM $\left(\mathrm{Cl}^{-}\right) \mathrm{s}$. The pre-aminated ETFE-g-poly(VBC) membranes were submerged in aqueous MPY solution (50\% vol.) and heated at $70{ }^{\circ} \mathrm{C}$ for $24 \mathrm{~h}$. The crude RG-AEMs were then washed with UPW before being heated in water for $6 \mathrm{~h}$ at $70{ }^{\circ} \mathrm{C}$. Subsequently, the membranes were soaked in aqueous $\mathrm{NaCl}\left(1.0 \mathrm{~mol} \mathrm{dm}^{-3}\right)$ solution for $12 \mathrm{~h}$ (with several changes of solution during this period to ensure the $\mathrm{Cl}^{-}$-anion forms of the RG-AEMs). The final RG-AEM $\left(\mathrm{Cl}^{-}\right) \mathrm{s}$ were obtained after thorough washing with UPW (over $16 \mathrm{~h}$ with at least 5 changes in UPW to removal all excess counter- and coions), and stored in UPW until required for use in experiments.

\section{Membrane designations}

The following nomenclature is used to unambiguously identify the different samples (see Scheme 1):

Ex a final RG-AEM $\left(\mathrm{Cl}^{-}\right)$synthesised with $x$ h grafting time;

Int $x$ the pre-aminated ETFE-g-poly(VBC) membranes used to fabricate $\mathbf{E} \boldsymbol{x}$;

AE16 the E16 RG-AEM $\left(\mathrm{Cl}^{-}\right)$that has been aged for $14 \mathrm{~d}$ at

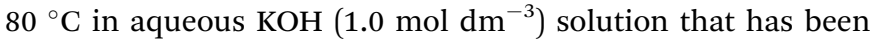
purged with $\mathrm{O}_{2}$ (see below).

\section{Water uptakes (WU)}

$\mathrm{RG}-\mathrm{AEM}\left(\mathrm{Cl}^{-}\right)$samples were removed from the storage water and excess surface water was removed by dabbing with filter paper. The hydrated masses $\left(m_{\text {hyd }}\right)$ were speedily recorded (to avoid dehydration on prolonged exposure to the atmosphere). The AEM samples were subsequently dried in a vacuum oven at $50{ }^{\circ} \mathrm{C}$ for $24 \mathrm{~h}$ before the dry masses $\left(m_{\mathrm{dry}}\right)$ were speedily recorded (dry AEMs are generally hygroscopic). All measurements were repeated on $n=3$ samples of each RG-AEM $\left(\mathrm{Cl}^{-}\right)$. The WU value for each sample was then calculated:

$$
\mathrm{WU}(\%)=\frac{m_{\mathrm{hyd}}-m_{\mathrm{dry}}}{m_{\mathrm{dry}}} \times 100
$$

\section{Ion-exchange capacities (IEC)}

The dehydrated RG-AEM $\left(\mathrm{Cl}^{-}\right) \mathrm{s}$ samples $\left(m_{\mathrm{dry}} / \mathrm{g}\right)$ collected straight from the WU measurements above were individually immersed into excess aqueous $\mathrm{NaNO}_{3}\left(2.4 \mathrm{~mol} \mathrm{dm}{ }^{-3}, 20 \mathrm{~cm}^{3}\right)$ solutions for $24 \mathrm{~h}$. The solutions, still containing the AEM samples, were then acidified with aqueous $\mathrm{HNO}_{3}(2.0 \mathrm{~mol}$ $\left.\mathrm{dm}^{-3}, 2.0 \mathrm{~cm}^{3}\right)$ and titrated using the aqueous $\mathrm{AgNO}_{3}(20.00 \pm$
Table 1 Details of the Raman lasers used in this study

\begin{tabular}{lllll}
\hline Wavelength/nm & 785 & 633 & 532 & 457 \\
Max. power/mW & 300 & 20 & 50 & 20 \\
Colour & Near-IR & Red & Green & Blue \\
Type & Line & Spot & Spot & Spot \\
Grating/lines $\mathrm{mm}^{-1}$ & 1200 & 1800 & 2400 & 2400 \\
Laser spot size $/ \mu \mathrm{m}$ & 1.28 & 1.03 & 0.87 & 0.74 \\
Filter cut-off $/ \mathrm{cm}^{-1}$ & 50 & 100 & 100 & 100
\end{tabular}

${ }^{a}$ Theoretical smallest laser spot diameter calculated $(1.22 \times \lambda / \mathrm{NA})$ assuming the use of a $50 \times(\mathrm{NA}=0.75)$ objective: the $785 \mathrm{~nm}$ line laser was used with the pinhole applied to expose the sample to a well-defined laser spot (rather than a laser line) but this reduces the power at the sample.

$0.06 \mathrm{mmol} \mathrm{dm}^{-3}$ ) solution. A Metrohm 848 TitrinoPlus autotitrator equipped with a Ag-Titrode was used for the titrations. The IEC for each sample was calculated from the end-point $\left(E_{\mathrm{p}}\right)$ :

$$
\operatorname{IEC}\left(\mathrm{mmol} \mathrm{g}^{-1}\right)=\frac{\left.E_{\mathrm{p}}\left(\mathrm{cm}^{3}\right) \times 0.02(\mathrm{~mol} \mathrm{dm})^{-3}\right)}{m_{\text {dry }}(\mathrm{g})}
$$

\section{Alkali stability testing}

A select RG-AEM $\left(\mathrm{Cl}^{-}\right)$, synthesised with $16 \mathrm{~h}$ of grafting reaction duration (E16), was subjected to alkali aging tests. A sample of E16 $(7 \times 7 \mathrm{~cm})$ was immersed in an excess of aqueous $\mathrm{KOH}$ $\left(1.0 \mathrm{~mol} \mathrm{dm}^{-3}\right)$ solution that was then purged with $\mathrm{O}_{2}$ for $1 \mathrm{~h}$. Previous studies have indicated that alkali degradation is more extreme in $\mathrm{O}_{2}$-containing aqueous alkali compared to inert-gas purged aqueous alkali. ${ }^{14}$ The polypropylene bottle was then immediately sealed (after purging) and placed in oven at $80{ }^{\circ} \mathrm{C}$ for $14 \mathrm{~d}$. After this alkali ageing process, the sealed bottle was cooled to room temperature and the aged sample (designated AE16) was then re-exchanged back to the $\mathrm{Cl}^{-}$-anion form using ion-exchange with aqueous solution $\mathrm{NaCl}\left(1.0 \mathrm{~mol} \mathrm{dm}^{-3}\right)$ followed by thorough washing with UPW for $16 \mathrm{~h}$ (with at least 5 changes of fresh UPW during this period). As well as the Raman experiments, the IEC of AE16 was also determined.

\section{Raman spectro-microscopic procedures}

Raman spectra and cross-sectional maps were recorded using an InVia Reflex Raman Microscope (Renishaw, UK) using 4 laser excitation wavelengths (Table 1). $\uparrow$ The Raman microscope was fitted with a cooled charged coupled detector (CCD) along with holographic notch filters and gratings tailored for each laser wavelength. The attached Leica DMLM optical microscope was equipped with different objective lenses and a trinocular viewer that accommodates a video camera, allowing direct viewing of the sample. Daily calibration of the instrument was conducted by recording the Raman spectrum of silicon in static mode. If necessary, an offset correction was performed to ensure that the position of the silicon peak to be $520 \pm 1 \mathrm{~cm}^{-1}$.

I The Renishaw Raman instrument used contains a 5th laser (244 nm deep UV) but this is not appropriate for this study: the laser damages the polymer samples, even at the lowest power setting. 
Table 2 The parameters used to obtain the maps for the pre-aminated ETFE-g-poly(VBC) membranes (Int $x$ where $x=$ the grafting reaction time/h) with par-sampling (sample-stage step size $=$ theoretical minimum laser spot diameter)

\begin{tabular}{lll}
\hline Wavelength/nm & 633 & 457 \\
Power at sample/mW & 20 & 2 \\
Step size/ $\mu \mathrm{m}$ & 1.03 & 0.74 \\
Exposure time/s & 1 & 1.5 \\
Total & 40 & 110
\end{tabular}

mapping time ${ }^{a} / \mathrm{min}$

${ }^{a}$ Calculated for $30 \times 65 \mu \mathrm{m}$ cross-sections with 1 spectral accumulation.

In this study, the laser beam was focused on the sample using a $50 \times(\mathrm{NA}=0.75)$ objective to collect the backscattered light so the resulting laser spot diameter was $c a .1 \mu \mathrm{m}$ (see Table 1). Other spectral collection parameters are presented in the figure captions (as appropriate). The raw data was processed using Renishaw's Wire 4.3 software: processing included baseline correction, smoothing, normalization, interpolation, and curve fitting of the peaks with the Gaussian-Lorentzian function to obtain accurate peak areas (where appropriate).

For the cross-sectional (through-plane) mapping experiments (Fig. 1), the membrane samples were held and pressed between two metal holders and fresh edges were obtained by sectioning using a scalpel. The membrane samples were mounted perpendicular to the sample-stage so that the exposed cross-sections are parallel to the stage. The stage was moved in the $x$ - and $y$-direction under computer control. Cross-sectional maps were collected with point mapping using the instrument's static scan mode over the spectral range $600-1700 \mathrm{~cm}^{-1}$. Maps were recorded over $30 \times 65 \mu \mathrm{m}$ cross-sectional areas (all the same so that the experiments could be timed).

For the pre-aminated ETFE-g-poly(VBC) membranes, the optimised mapping parameters used are presented in Table 2 (for par-sampling where sample step size $=$ theoretical min. laser spot diameter). Maps with different sample step sizes were also performed on a sample of Int 4 to determine an appropriate step size to be used for mapping experiments (Fig. 2): both under-sampling (step size $>$ theoretical min. laser spot diameter) and over-sampling (step size $<$ theoretical min. laser spot diameter) were studied.
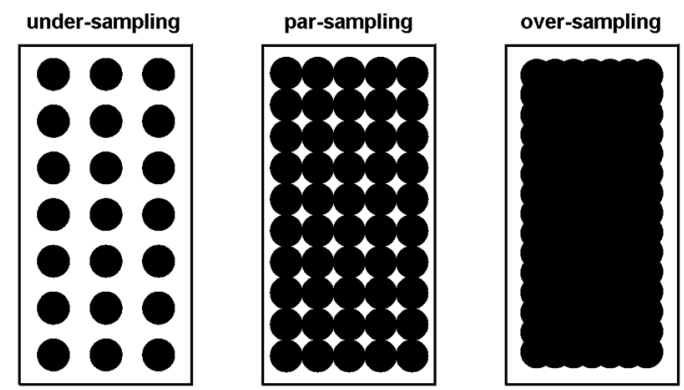

Fig. 2 A diagram summarising the different sampling modes used in the Raman mapping experiments.
For the final E16 and the alkali-aged AE16 samples, crosssectional maps were collected using the $785 \mathrm{~nm}$ line laser (pinhole applied, $300 \mathrm{~mW}$ power) with a step size of $1.28 \mu \mathrm{m}$ (par-sampling) in both the $x$ - and $y$-directions. These spectral maps were collected using a $50 \times$ objective, $5 \mathrm{~s}$ exposure times, and averaging over 2 accumulations (mapping time of $220 \mathrm{~min}$ ).

\section{Results and discussion}

\section{Membrane characterisation}

A series of pyrrolidinium-based $\operatorname{RG}-\mathrm{AEM}\left(\mathrm{Cl}^{-}\right) \mathrm{s}$ with various degrees of grafting (DoG) were prepared via the peroxidation radiation-grafting of VBC monomer onto ETFE films followed by amination with 1-methylpyrrolidine (MPY) (Scheme 1). The IECs and WUs of the AEMs are presented in Table 3 (Fig. S2 in the ESI $\uparrow$ shows the variation in IEC $v s$. DoG for the RG-AEM $\left(\mathrm{Cl}^{-}\right)$ s). The IECs of E16 and E72 were 80\% of the theoretical IECs (calculated from DoG) due to side-reactions as explained previously (e.g. conversion of $-\mathrm{CH}_{2} \mathrm{Cl}$ to $\left.-\mathrm{CH}_{2} \mathrm{OH}\right) .{ }^{9}$ The WU is related to the number of ion-exchange sites. As expected, the WUs of the $\operatorname{AEM}\left(\mathrm{Cl}^{-}\right) \mathrm{s}$ increased with IEC (Fig. S2 in the ESI $\dagger$ ), due to the higher hydrophilic content levels. The IEC and WU values obtained for RG-AEM $\left(\mathrm{Cl}^{-}\right) \mathrm{s}$ are bulk averages and do not give any information on the spatial distribution of the grafted quaternary ammonium groups. This is why techniques, such as Raman microscopy, are required to evaluate such micro-phase segregation in IEMs, e.g. the RG-AEMs in this study.\|

\section{Raman spectroscopy to elucidate optimal laser wavelength}

A vital consideration for Raman spectro-microscopy is the selection of laser excitation wavelength $(\lambda) .^{15}$ This choice is not always straightforward and must balance the following requirements:

- Maximised intensity of the Raman scattered radiation to allow for more rapid collection of spectral data: this is dictated (at each wavelength) by the Raman efficiency and the highest level of laser power that can be applied that does not cause sample damage;

- Minimised level of fluorescence to facilitate spectral data processing and to ensure all relevant peaks are observed;

- Maximised spectral resolution to ensure adequate resolution of overlapping peaks;

- Ability to obtain the spatial resolution required, which is partially controlled by the laser spot diameter obtainable (Table 1 ): the minimum Airy disk diameter $=1.22 \times \lambda / \mathrm{NA}$ (where NA is the aperture of the objective being used). ${ }^{13}$

The intensity of Raman scattering is proportional to $\lambda^{-4},{ }^{16}$ hence, a shorter wavelength will yield a stronger Raman signal: the intensity of the scattered radiation with a $633 \mathrm{~nm}$ laser is only $27 \%$ of the intensity obtained with a $457 \mathrm{~nm}$ laser. For the

|| If determination of nano-scale phase segregations of hydrophilic $v s$. hydrophobic components is required, techniques such as small angle neutron scattering (SANS) and transmission electron microscopy (TEM) are required. Such data is beyond the scope of this current study, which is focussed on the homogeneity of the grafting and degradation processes (where we show that micro-scale characterisation is sufficient). 
Table 3 A summary of the pyrrolidinium-based RG-AEM(Cl-)s synthesised

\begin{tabular}{lllll}
\hline RG-AEM $\left(\mathrm{Cl}^{-}\right) \mathrm{s}$ & E1 & E4 & E16 & E72 \\
Grafting time/h & 1 & 4 & 16 & 72 \\
DoG $(\%)$ & 18 & 44 & 99 \\
IEC $\left(\mathrm{Cl}^{-}\right.$anion $) / \mathrm{mmol} \mathrm{g}^{-1}$ & $0.91 \pm 0.05$ & $1.70 \pm 0.06$ & $2.06 \pm 0.02$ \\
WU $(\%)$ & $8 \pm 3$ & $79 \pm 5$ & $104 \pm 7$ & $2.36 \pm 0.07$ \\
$\lambda_{\text {water }}{ }^{-1}$ & 5 & 26 & 28
\end{tabular}

${ }^{a}$ Number of $\mathrm{H}_{2} \mathrm{O}$ molecules per $\mathrm{Cl}^{-}$anion [not to be confused with laser wavelength $\lambda$ ], calculated as: $\lambda_{\text {water }}=$ WU $(\%) /(100 \times 18.02 \times$ IEC), where IEC is in $\mathrm{mol} \mathrm{g}^{-1}$.
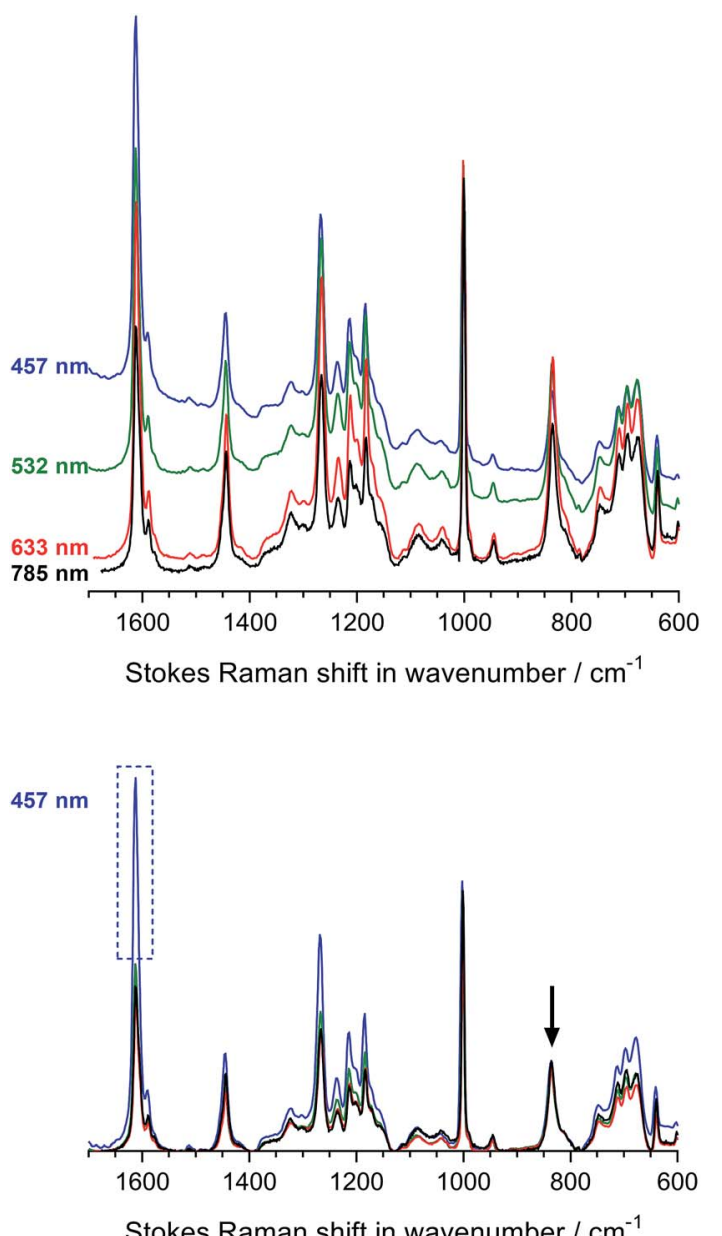

Fig. 3 The Raman spectra of Int16 both with (bottom graph) and without (top graph) baseline correction and normalisation. The baseline-corrected spectra were normalised to the intensity of the $\mathrm{CF}_{2}$ stretch peak at $835 \mathrm{~cm}^{-1}$ peak to aid visual comparison (the peak indicated by arrow). The enhancement in the $1612 \mathrm{~cm}^{-1}$ peak when using the $457 \mathrm{~nm}$ laser is shown by the dashed box.

higher wavelength laser, this intrinsic lower intensity can often be offset by increasing the laser power as long as sample damage does not occur (higher wavelength radiation yields less $J$ of energy per photon). Fluorescence is commonly a decisive factor and arises from the coincidence of the excitation energy with electronic transitions. A way of avoiding this problem is to choose a longer wavelength (e.g. near-IR) with the compromise of lower spatial resolutions, or to move to UV wavelengths with

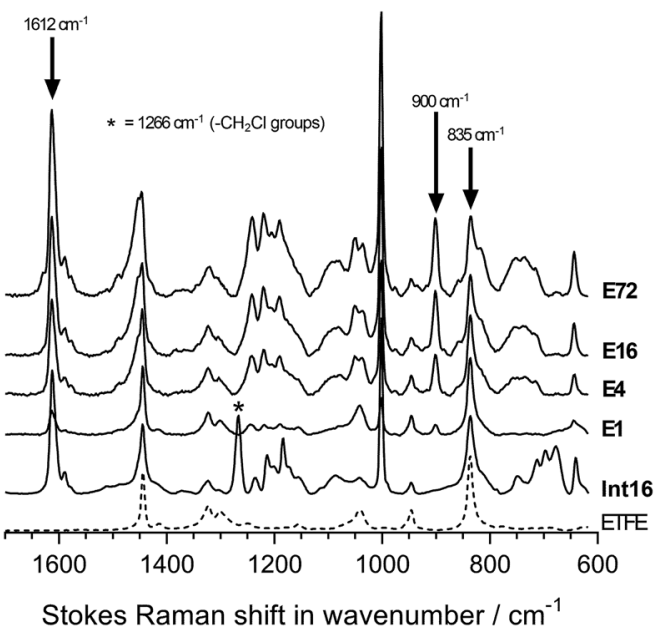

Fig. 4 The Raman spectra of (from bottom to top): the pristine ETFE, Int16, E1, E4, E16 and E72. Spectra were recorded with a $785 \mathrm{~nm}$ laser at $300 \mathrm{~mW}$ power (the only laser that could be used for all samples). The spectra were normalised to the intensity of ETFE peak at $835 \mathrm{~cm}^{-1}$ to aid visual comparison. The arrows indicate the key peaks used for the Raman cross-section mapping experiments.

the compromise of lower spectral resolutions and with the increased risk of sample damage occurring. Finally, the spatial resolution is especially important for point mapping, where a small laser spot diameter is often required.

Fig. 3 displays the Raman spectra of the Int16 membrane at the four-different wavelengths both with and without baseline correction and normalisation. We selected Int16 for this initial laser $\lambda$ study as this pre-aminated membrane visually showed evidence (increase in opacity) of a high level of grafting. The use of 457 and $532 \mathrm{~nm}$ lasers led to moderate fluorescence, whereas the 633 and $785 \mathrm{~nm}$ lasers yielded spectra with minimal fluorescence. After baseline correction and normalisation, a number of Raman peaks were obtained with enhanced intensities with the $457 \mathrm{~nm}$ laser (especially the aromatic peak at $1612 \mathrm{~cm}^{-1}$ ) indicating an intriguing but small Raman enhancement effect. Therefore, the 457 and $633 \mathrm{~nm}$ spot lasers were down-selected for the characterisation of pre-aminated ETFE-g-poly(VBC) membranes using Raman cross-sectional mapping. The $457 \mathrm{~nm}$ laser could be used up to $10 \%$ maximum power before sample damage occurs, while the $633 \mathrm{~nm}$ laser could be used at maximum power.

Regarding the (orange-brown coloured) RG-AEM $\left(\mathrm{Cl}^{-}\right) \mathrm{s}$, the Raman spectra recorded using 457 and $532 \mathrm{~nm}$ lasers showed 

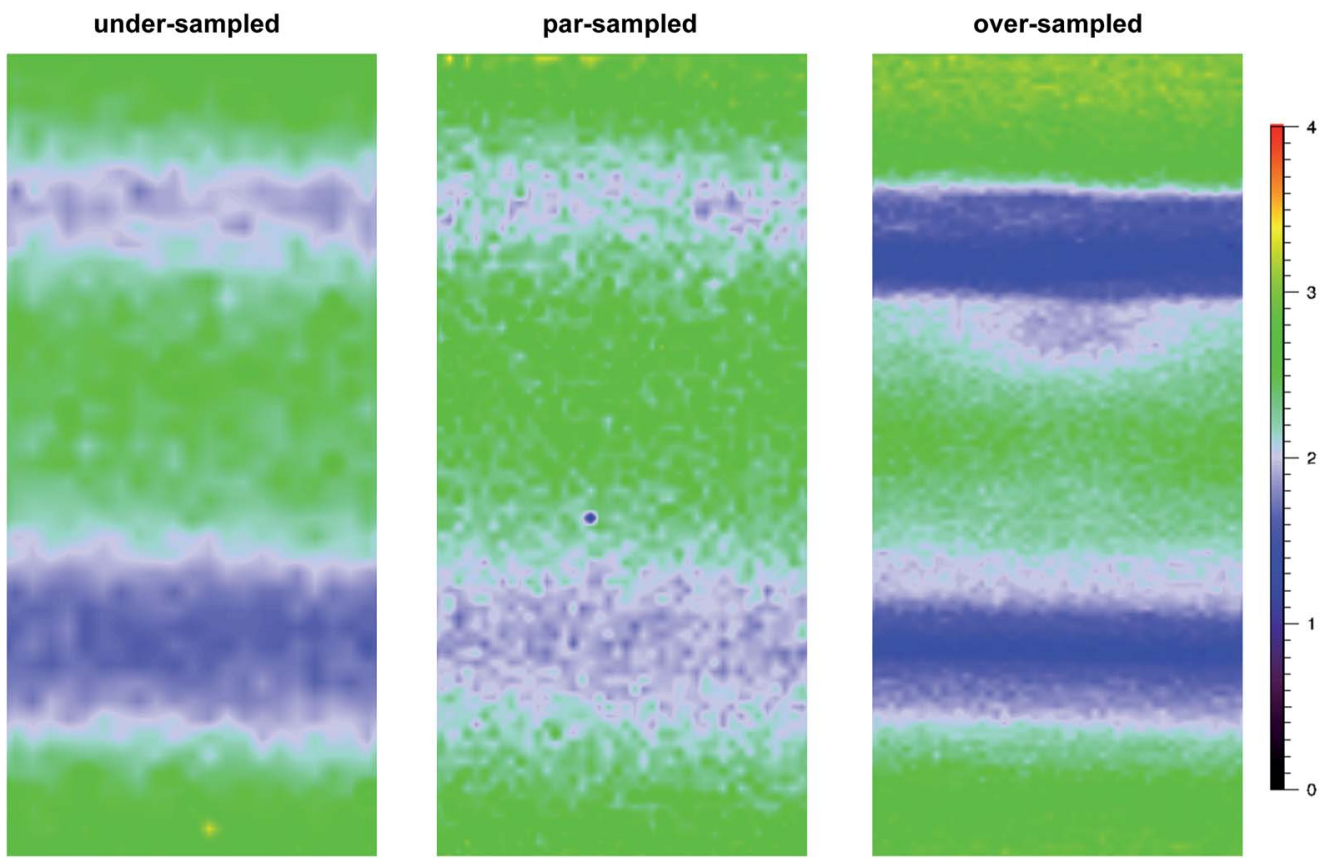

Fig. 5 Raman cross-sectional interpolated maps of Int4 recorded using the $457 \mathrm{~nm}$ laser ( $2 \mathrm{~mW}$ power at sample) and sample-stage step-sizes of: (left) under-sampled $1.5 \mu \mathrm{m}$; (middle) par-sampled $0.74 \mu \mathrm{m}$; and (right) over-sampled $0.5 \mu \mathrm{m}$. The colour scale represents the peak area ratio $=A_{1612} / A_{835}$ (content of benzene rings vs. ETFE) where $A_{y}$ is the area under the peak located at wavenumber $=y \mathrm{~cm}^{-1}$. Each map is $30 \times 65 \mu \mathrm{m}$ in size ( $y$-axis is the through-plane direction).

excessively strong fluorescence backgrounds that could not be reliably subtracted (see Fig. S3 in the ESI†). In contrast, the $785 \mathrm{~nm}$ laser yielded spectra with lower levels of baseline noise. Furthermore, it was impossible to record adequate spectra with the dark brown AE16 sample with all but the $785 \mathrm{~nm}$ laser due to the very high levels of fluorescence observed. The $785 \mathrm{~nm}$ laser proved to be the only available option that was suitable for recording spectral maps of both the pre- and post-alkali-treated RG-AEMs. On the downside, the use of this longer wavelength laser (with pinhole applied to make it a spot laser) gave weak signals and so longer acquisition times were required (even when using maximum power).

\section{Chemical characterisation using Raman spectroscopy}

The chemical structures of the pristine ETFE along with Int16, E1, E4, E16, and E72 were evaluated using Raman spectroscopy on the surfaces of the membranes (Fig. 4). The ETFE spectrum is dominated by the presence of two sharp peaks: $\mathrm{CF}_{2}$ stretches at $835 \mathrm{~cm}^{-1}$ (ref. 17) and $\mathrm{CH}_{2}$ bends at $1444 \mathrm{~cm}^{-1}$. The grafting of the VBC onto the peroxidated ETFE film introduced new peaks at 1612,1266 , and $1000 \mathrm{~cm}^{-1}$,** which correspond to the aromatic ring breathing, $\mathrm{CH}_{2} \mathrm{Cl}$ deformations, ${ }^{6,9}$ and metadisubstituted benzene rings, ${ }^{18}$ respectively. The spectra of RG$\operatorname{AEM}\left(\mathrm{Cl}^{-}\right)$s reveals that the $\mathrm{CH}_{2} \mathrm{Cl}$ peak at $1266 \mathrm{~cm}^{-1}$ (* in Fig. 4) disappears indicating successful amination with the MPY. In addition, a new band at $900 \mathrm{~cm}^{-1}$ was observed, which derives

\footnotetext{
** This peak is only present with 1,3-disubstituted benzene rings (in the 3-VBC monomer and 3 -VBC grafted chains) and is not observed for the grafted 4-VBC chains (recall that mixed 3- and 4-VBC monomers are being grafted).
}

from the presence of cationic pyrrolidinium groups. All this data corroborates the Raman data previously reported for ETFEMPY-based RG-AEMs. ${ }^{6}$

\section{Raman mapping of the pre-aminated ETFE-g-poly(VBC) membranes}

Raman mapping was first performed on cross-sectional samples of the pre-aminated ETFE-g-poly(VBC) membranes to measure the through-plane distributions of the poly(VBC) grafts (Fig. 1). This was assessed using the peak area ratio $A_{1612} / A_{835}$ : this is the area of the $1612 \mathrm{~cm}^{-1}$ aromatic peak (deriving from the grafted poly(VBC) chains) vs. the area of the $835 \mathrm{~cm}^{-1}$ peak (deriving from the backbone of the ETFE films). Peak areas were calculated by curve fitting using the Gaussian-Lorentzian function (after the spectra had been baseline corrected).

Fig. 5 shows the interpolated Raman maps obtained using the $457 \mathrm{~nm}$ laser for cross-sections of Int4 with the following stage $(x-y)$ step sizes: $0.5 \mu \mathrm{m}$ (over-sampling), $0.74 \mu \mathrm{m}$ (parsampling) and $1.5 \mu \mathrm{m}$ (under-sampling). Recall, Fig. 2 schematically highlights the difference between these sampling modes. Note, these maps were produced from different crosssections of Int4, and so the grafting distributions show a natural level of variation. For Int4, the distribution of pol$y(V B C)$ grafts shows more intensity at the surface and the middle of the membranes with bands of slightly lower intensity separating these regions. It is hypothesised that this is an effect of the diffusion of monomer. The monomer fronts diffuse from both surfaces of the ETFE film to finally meet in the middle, which increases the concentration of monomer at this location: 

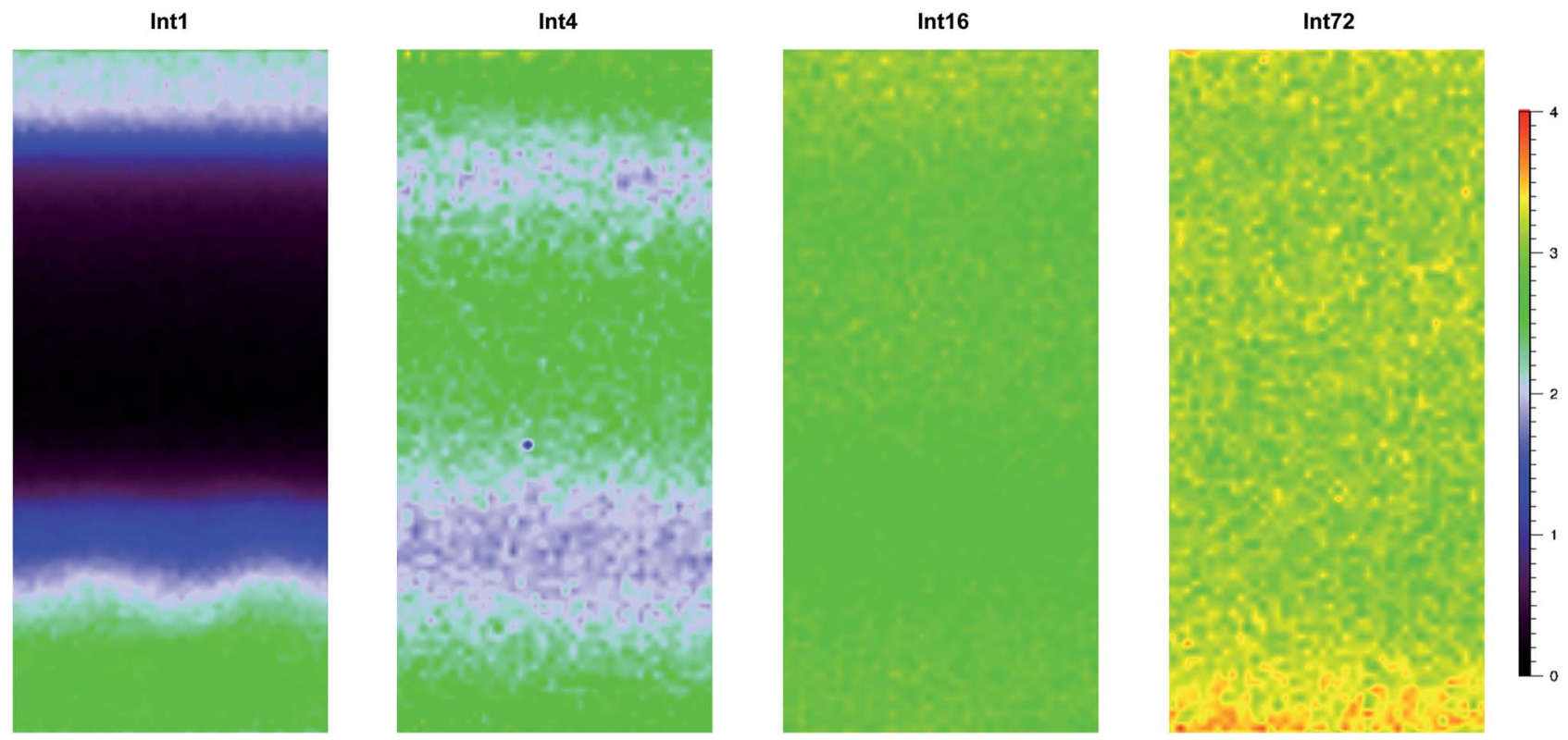

Fig. 6 Raman cross-sectional interpolated maps recorded using the $457 \mathrm{~nm}$ laser ( $2 \mathrm{~mW}$ power at sample) with par-sampling of (from left to right): Int1, Int4, Int16, and Int72. The colour scale represents the peak area ratio $=A_{1612} / A_{835}$ (content of benzene rings vs. ETFE) where $A_{y}$ is the area under the peak located at wavenumber $=y \mathrm{~cm}^{-1}$. Each map is $30 \times 65 \mu \mathrm{m}$ in size (y-axis is the through-plane direction).

this leads to more rapid grafting for a period of time in the centre of the membrane. This effect was previously seen in a study that used propan-2-ol in the grafting medium, ${ }^{6}$ rather than the water used in this current study.

The data recorded using over-sampling demonstrated a higher fidelity Raman image, at the expense of experiment duration: map time was $220 \mathrm{~min}$ (compared to $30 \mathrm{~min}$ for the under-sampled image). A step size of $0.74 \mu \mathrm{m}$ (par-sampling) was chosen for this study as it balances image fidelity with measurement time (map time of $110 \mathrm{~min}$ ). Despite this, undersampling may still be useful if a future necessity arose that

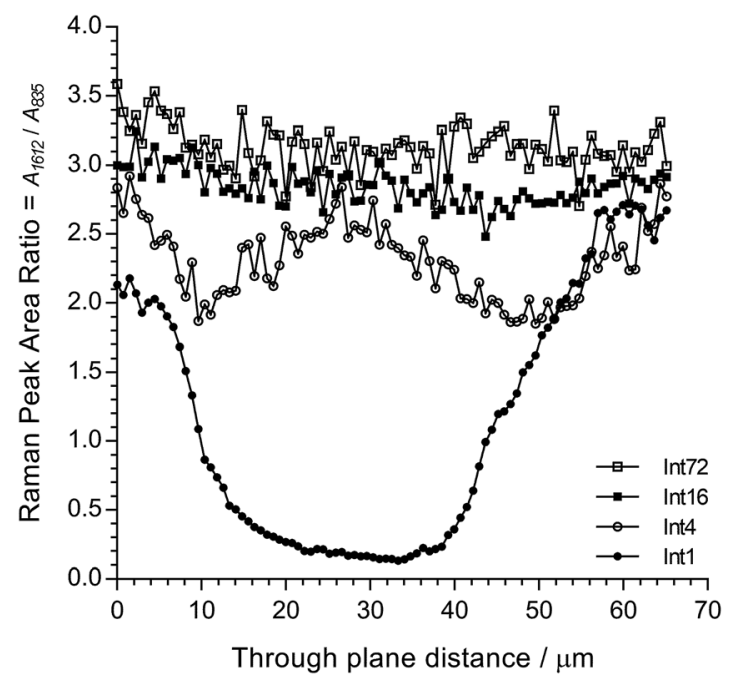

Fig. 7 Line-map data for Int1, Int4, Int16, and Int72 taken from the centres of the cross-sectional maps presented in Fig. 6 (in the through-plane $y$-axis direction).

required regularly conducted quality assurance measurements on a large number of samples (e.g. routine checks for homogeneous grafting of multiple batches of RG-AEM) or if measurements on larger cross-sectional areas of individual samples were desired: the fidelity of the under-sampled maps is still adequate for such tasks.

The Raman maps collected with the $633 \mathrm{~nm}$ laser are presented in Fig. S5 in the ESI: $\dagger$ with this laser, faster mapping times of $20 \mathrm{~min}, 40 \mathrm{~min}$, and $76 \mathrm{~min}$ were obtained with under(1.50 $\mu \mathrm{m}$ step-size), par- $(1.03 \mu \mathrm{m})$, and over-sampling $(0.74 \mu \mathrm{m})$, respectively. These mapping times were quicker as the $633 \mathrm{~nm}$ laser could be applied at higher powers (at the sample): $20 \mathrm{~mW}$ compared to the maximum $2 \mathrm{~mW}$ that could be used with the $457 \mathrm{~nm}$ laser (due to sample damage at higher powers). Parsampling (stage step size of $1.03 \mu \mathrm{m}$ ) was again down-selected to map the distribution of the grafted poly(VBC) chains with the $633 \mathrm{~nm}$ laser.

Table 4 Statistical data extracted from the Raman maps presented in Fig. 6 (calculated for the 95\% confidence level) for the two most homogeneously grafted pre-aminated ETFE-g-poly(VBC) membranes

ETFE-g-poly(VBC)

Number of measurements

Mean

Standard deviation

Relative standard deviation RSD (\%)

Confidence intervals

D'Agostino-Pearson omnibus test: ${ }^{a} p=$

Passed normality test $(\alpha=0.05)$ ?

Mann-Whitney $U$ test: ${ }^{b} p=$

Means significantly different?

${ }^{a}$ Test for normality. ${ }^{b}$ Non-parametric two-tailed Mann-Whitney $U$ test. 

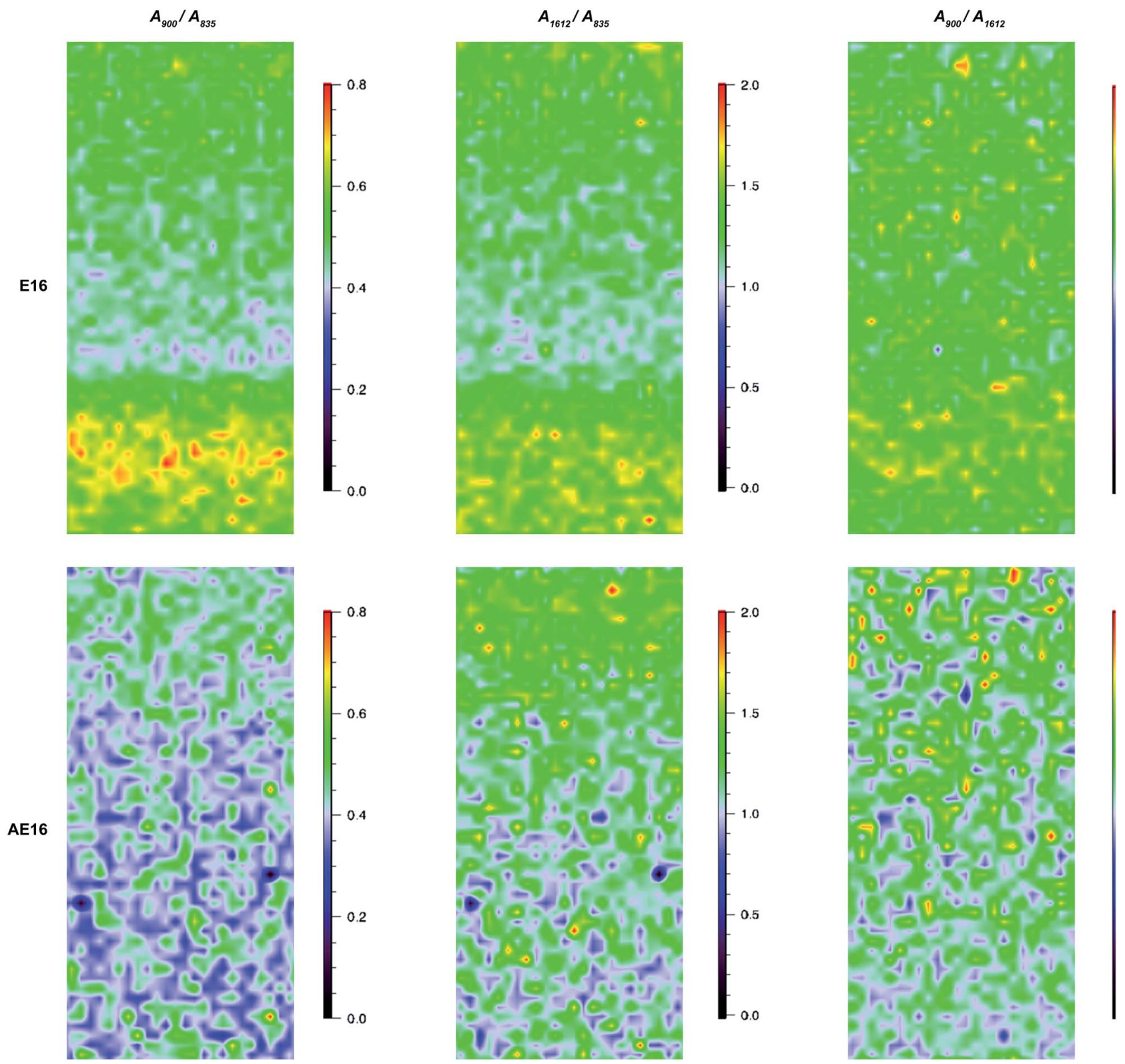

Fig. 8 Raman cross-sectional interpolated maps of E16 (top row) and AE16 (bottom row) recorded using the $785 \mathrm{~nm}$ laser (300 mW power, pinhole applied) with par-sampling. The colour scale represents (from left to right columns): $A_{900} / A_{835}$ (pyrrolidinium vs. ETFE); $A_{1612} / A_{835}$ (benzene vs. ETFE); $A_{900} / A_{1612}$ (pyrrolidinium vs. benzene). Each map is $30 \times 65 \mu \mathrm{m}$ in size ( $y$-axis is the through-plane direction).

Fig. 6 shows cross-sectional maps (457 nm, par-sampled) obtained with the pre-aminated ETFE-g-poly(VBC) membranes synthesised using increasing grafting reaction times (Int1, Int4, Int16, and Int72). Fig. S4 in the ESI† gives the box and whisker plots that summarises this data for all the pre-aminated ETFE-gpoly(VBC) membranes studied. For additional clarity, Fig. 7 presents line-map data $(457 \mathrm{~nm})$ taken from the centres of the cross-sectional maps.

From this Raman data, it was observed that Int1 (with the lowest $\mathrm{DoG}=18 \%)$ contained poly $(\mathrm{VBC})$ grafted chains at the surface and a relatively ungrafted core. Increasing the grafting time to $4 \mathrm{~h}$ resulted in a wider through-plane distribution of grafting in the resulting membrane (Int4), but the grafting distribution was still not fully homogeneous (discussed previously). As the DoG approaches a value of $99 \%$ (Int16), a more homogeneous grafting of the poly(VBC) chains was achieved. The 4-probe (in-plane) chloride-anion conductivities of fully hydrated E1, E4, and E16 (measured using the method described in ref. 9) were $14 \pm 3,39 \pm 2$, and $49 \pm 2 \mathrm{mS} \mathrm{cm}^{-1}(n=$ $3)$, respectively, which is consistent with this Raman data.

Prolonging the grafting time to $72 \mathrm{~h}($ Int72, DoG $=155 \%)$ led to higher grafting levels but this has detrimental consequences: e.g. E72 was observed to possess an excessive water content with $\lambda_{\text {water }}>30$ (Table 3), where $\lambda_{\text {water }}$ is the average number of $\mathrm{H}_{2} \mathrm{O}$ molecules per anion-exchange site. Prior studies have shown that not all of the $\mathrm{H}_{2} \mathrm{O}$ molecules are directly associated with the 


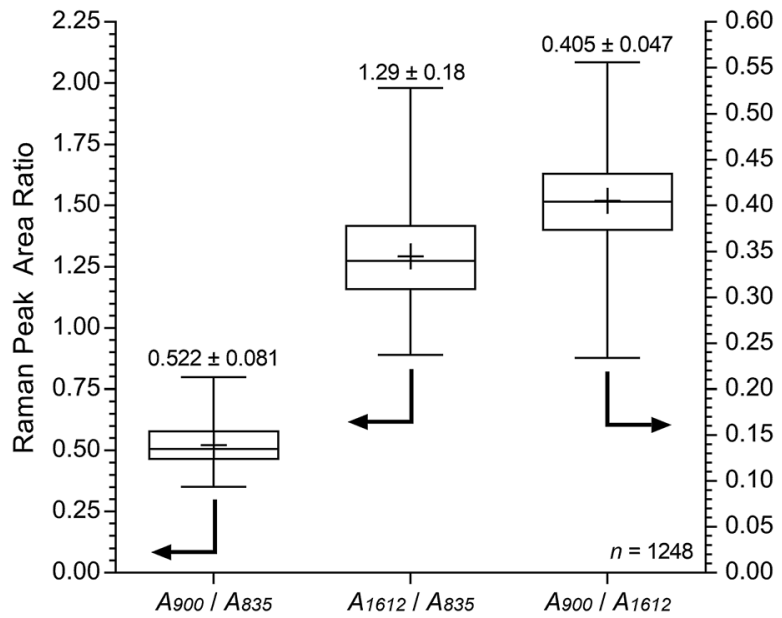

Fig. 9 Box and whisker plot summarising the cross-sectional Raman spectral data (785 nm laser) for E16 (extracted from Fig. 8). The + symbols give the means, the middle horizontal lines give the medians, the boxes give the interquartile ranges, and the whiskers give the min and max values recorded. The numeric data presented gives the mean and sample standard deviations $(n=1248)$.

ionic groups: many $\mathrm{H}_{2} \mathrm{O}$ molecules are "non-useful" in that they form domains of water aggregates that lead to excessive RG-AEM swelling, which results in a weakening of the mechanical properties. ${ }^{19}$ Table 4 gives the results of a statistical analysis comparing the poly(VBC) grafting levels between Int16 and Int72 using all of the $A_{1612} / A_{835}$ peak area ratios recorded in the production of their Raman maps in Fig. 6. Int72 has a (statistically significant) higher amount of grafting than Int16.

All of the above indicates that the grafting front mechanism is operating when VBC is grafted onto $50 \mu \mathrm{m}$ thick ETFE films. Additional maps, acquired using the $633 \mathrm{~nm}$ laser on different cross-sections of the pre-aminated ETFE-g-poly(VBC) membranes (Fig. S6 in the ESI $\dagger$ ), confirm these observations. This Raman data is consistent with the bulk IEC values recorded for the final RG-AEM $\left(\mathrm{Cl}^{-}\right)$s that were made by the amination of Int1, Int4, Int16, and Int72: IECs increase in the order E1 $<$ E4 $<$ E16 < E72. However, this Raman microscopy data provides additional evidence that the homogeneity of grafting is poor at low grafting reaction times.

\section{Raman studies on a $\mathrm{RG}-\mathrm{AEM}\left(\mathrm{Cl}^{-}\right)$: pre- and post-alkali-aged E16}

Cross-sectional mapping. The most important requirement for a high-performance RG-AEM is the homogeneous crosssectional distribution of functional groups (Fig. 1). ${ }^{9}$ The following peak area ratios were used to characterise E16 (top row of Fig. 8), where $A_{y}$ is the area of the peak at $y / \mathrm{cm}^{-1}$ calculated by curve fitting using the Gaussian-Lorentzian function (after the spectra had been baseline corrected):

(1) Ratio $=A_{900} / A_{835}$ : pyrrolidinium groups $v$. ETFE;

(2) Ratio $=A_{1612} / A_{835}$ : benzene rings $v s$. ETFE;

(3) Ratio $=A_{900} / A_{1612}$ : pyrrolidinium groups $v$ s. benzene rings;
Table 5 Statistical data for the peak area ratio $A_{900} / A_{835}$ data extracted from the Raman cross-sectional maps (785 $\mathrm{nm}$ laser) recorded on preand post-alkali-aged E16 (calculated for the 95\% confidence level)

\begin{tabular}{lll}
\hline & E16 & AE16 \\
Number of measurements & 1248 & 1248 \\
Mean & 0.522 & 0.415 \\
Standard deviation & 0.081 & 0.076 \\
RSD $(\%)$ & 16 & 18 \\
Confidence intervals & \pm 0.005 & \pm 0.004 \\
D'Agostino-Pearson omnibus $^{a} p=$ & $<0.0001$ & $<0.0001$ \\
test: $^{a} p=$ & & \\
Passed normality test $(\alpha=0.05) ?$ & No & No \\
Mann-Whitney $U$ test: ${ }^{b} p=$ & $<0.0001$ & \\
Means significantly different? & Yes &
\end{tabular}

${ }^{a}$ Test for normality. ${ }^{b}$ Non-parametric two-tailed Mann-Whitney $U$ test.

(1) and (2) represent the homogeneity of grafting and (3) represents the homogeneity of amination of the benzene rings.

For the pre-alkali-aged E16, it was evident that functionalisation was less homogeneous compared to the grafting studies on Int16. This may be due to segregation of the hydrophilic and hydrophobic phases in the RG-AEM sample that occurs after the amination process. $\uparrow \dagger$ The obvious "health warning" must also be kept in mind in that the apparent lower homogeneity may be down to sampling: the specific cross-sectional sample of E16 that was mapped could have been a low homogeneity section of the RG-AEM. Fig. 9 gives the box and whisker plots for data extracted from the top row of Fig. 8.

The data on the alkali degraded AE16 (bottom row of Fig. 8) clearly shows that degradation is evident when the $\mathbf{E 1 6}$ was aged in $\mathrm{O}_{2}$-purged aqueous $\mathrm{KOH}\left(1.0 \mathrm{~mol} \mathrm{dm}^{-3}\right)$ at $80{ }^{\circ} \mathrm{C}$ for $14 \mathrm{~d}$. This data also shows that the degradation occurs throughout the cross-section of the RG-AEM. Fig. S7 in the ESI $\uparrow$ presents the box and whisker plots comparing the peak area ratios for E16 and AE16 (extracted from the Raman cross-sectional map data presented in Fig. 8). The larger variances seen in the AE16 data is due to the difficulty in reliably fitting all of the spectral data due to the significant fluorescence backgrounds encountered. Statistical analysis of the peak area ratio $A_{900} / A_{835}$ data (the ratio expected to change the most on RG-AEM degradation) is summarised in Table 5. This analysis shows that this peak area ratio data is significantly different for AE16 compared to E16 due to alkali degradation. The degradation observed was due to both: (1) loss of the positively-charged pyrrolidinium functionality (Scheme 2: nucleophilic hydroxide attack positions A, B, and C and Hofmann elimination attack position E); (2) loss of grafted benzene rings from the RG-AEM, complete with pyrrolidinium groups (Scheme 2: hydroxide attack position D). This is consistent with the observations reported in recent studies on both ETFE- and LDPE-based RG-AEMs. ${ }^{6,14}$

$\dagger \dagger$ Note: with the use of the IR $(785 \mathrm{~nm})$ laser, the scale-bar for the $A_{1612} / A_{835}$ peak area ratio (middle column in Fig. 8) is compressed to the range 0-2, compared to the range $0-4$ in Fig. 6, that was required to accommodate the higher ratios observed for Int72 with the use of the blue (457 nm) laser. 


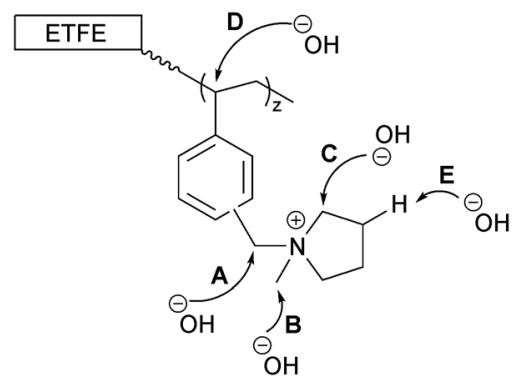

Scheme 2 The possible sites that nucleophilic $\mathrm{OH}^{-}$anions can attack the grafted chains in RG-AEMs. ${ }^{6}$

Surface Raman data. So far, this study has considered the cross-sectional (through-plane) distributions of functionality. However, the homogeneity of functionalisation across the surfaces of the RG-AEMs should also be evaluated (Fig. 10). Detailed mapping over large areas of RG-AEM surfaces is not viable for routine measurements. A more practical method is to record a number of spectra on different parts of the surface of a RG-AEM sample. In this study, Raman spectra $785 \mathrm{~nm}$, $300 \mathrm{~mW}$, pinhole applied) were recorded at 25 sampling points on the surfaces of E16 and AE16 (recorded as a $5 \times 5$ grid over ca. $1 \mathrm{~cm}^{2}$ sized samples). Each spectrum was analysed for the three peak area ratios described above.

Fig. 11 shows the results recorded on the surface of a sample of E16. This data shows good homogeneity with RSDs $<10 \%$ for all three peak area ratios. However, this Raman data shows that the surface analysis of E16 yields larger area ratios $A_{900} / A_{835}$ and $A_{1612} / A_{835}$, that are related to the level of grafting, compared to the cross-sectional analysis (Fig. 9). This suggests there is an excess of grafting directly at the surface of E16 (where the laser only penetrates a couple of $\mu \mathrm{m}$ into the membrane when focused on the surface). Therefore, for RG-AEMs, we strongly recommend that surface data should always be collected alongside cross-sectional mapping data (to obtain the fullest possible picture of the distribution of the grafted chains).

Fig. S8 in the ESI $\dagger$ presents the box and whisker plots comparing the peak area ratios from the surface analyses of E16 and AE16. Statistical data for the peak area ratio $A_{900} / A_{835}$ is summarised in Table 6. This analysis again shows that this diagnostic peak area ratio is significantly different for AE16 compared to E16 due to alkali degradation. There was a $25 \%$ loss of this peak area ratio on surface degradation, while only a $21 \%$ loss was observed in the analysis of the cross-sectional data. It is not unexpected that degradation would be more

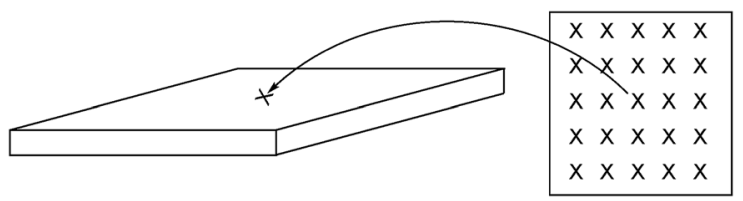

Fig. 10 A diagram showing the sampling of the Raman spectra recorded on the surfaces of E16 and AE16 (ca. $1 \mathrm{~cm}^{2}$ samples in this study).

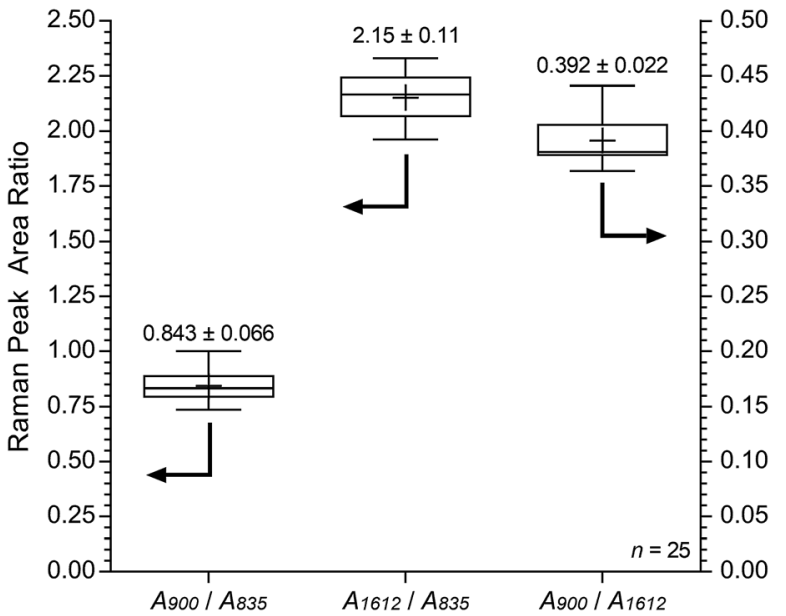

Fig. 11 Box and whisker plot summarising the surface Raman spectral data (785 nm laser) for E16. The numeric data presented gives the mean and sample standard deviations $(n=25)$.

Table 6 Statistical data for the peak area ratio $A_{900} / A_{833}$ data extracted from the Raman spectra (785 nm laser) recorded on the surfaces of the pre- and post-alkali-aged E16 (calculated for the 95\% confidence level)

\begin{tabular}{lll}
\hline & E16 & AE16 \\
Number of measurements & 25 & 25 \\
Mean & 0.843 & 0.63 \\
Standard deviation & 0.066 & 0.15 \\
RSD (\%) & 7.9 & 24 \\
Confidence intervals & \pm 0.027 & \pm 0.063 \\
D'Agostino-Pearson omnibus test: $^{a}$ & 0.512 & 0.407 \\
$p=$ & & \\
Passed normality test $(\alpha=0.05) ?_{F \text {-test: } p=}$ & Yes & Yes \\
Variances statistically different? $_{t \text {-test: }}^{b} p=$ & 0.0001 & \\
Means statistically different? & Yes & \\
\end{tabular}

${ }^{a}$ Test for normality. ${ }^{b}$ Un-paired two-tailed $t$ test with Welch'scorrection (due to non-equal variances).

severe at the surface of RG-AEMs. AE16 possessed an IEC of 1.65 $\pm 0.17 \mathrm{mmol} \mathrm{g}^{-1}(n=3)$, which was $20 \%$ lower than the $2.06 \pm$ $0.02 \mathrm{mmol} \mathrm{g}^{-1}$ recorded for the pre-alkali treated E16. This (bulk) IEC data directly correlates with the loss of the peak area ratio $A_{900} / A_{835}$ in the Raman cross-sectional data.

\section{Conclusions}

This study highlights the usefulness of using Raman spectromicroscopy in the study of radiation-grafted membranes (anion-exchange membranes in this case). This technique is especially helpful for the study of the homogeneity of the crosssectional grafting (on the micro-scale). This technique has the potential to be used as a quality assurance tool regarding the grafting process (with cross-sectional mapping times of $<1 \mathrm{~h}$ being possible with under-sampling). This technique can also be useful for the study of the homogeneity of any post-grafting 
functionalisation process (e.g. amination) as well as for the (post-mortem) investigation of membrane degradation processes. For radiation-grafted membranes, the analysis of the surfaces must always be conducted in addition to any crosssectional analysis, in order to obtain the whole picture regarding the distribution of membrane functionality (and membrane degradation).

For the radiation-grafted anion-exchange membranes (RGAEM), made from $50 \mu \mathrm{m}$ thick ETFE films in this investigation, a vinylbenzyl grafting time of $16 \mathrm{~h}$ appears to be optimal (with the specific synthesis conditions used). The Raman data is consistent with the operation of the grafting front mechanism. Amination with 1-methylpyrrolidine was homogeneous and yielded RG-AEMs with ion-exchange capacities (IEC) of $>2.0 \mathrm{mmol} \mathrm{g}^{-1}$. There was an excess of grafting at the surfaces of the RG-AEMs (at least in the first few $\mu \mathrm{m}$ ). The level of degradation, measured using Raman spectro-microscopy of the RGAEM cross-sections after ageing in hot aqueous alkali, matched the loss of IEC; however, the high levels of photoluminescence that occurs with the (dark-brown-coloured) alkali degraded RG-AEMs led to more problematic spectral analysis. Degradation occurred throughout the RG-AEM cross-sections but appeared to be more severe at the surfaces. The 457 and $633 \mathrm{~nm}$ laser wavelengths were the most useful for the study of the pre-aminated grafted membranes, while the $785 \mathrm{~nm}$ laser wavelength was the only option that could be used for the study of the pre- and post-alkali degraded RG-AEMs.

\section{Author contributions}

Dr Bance-Soualhi supervised the student and conducted a number of the experiments (surface maps and degradation data), as well as making a major contribution to authoring of this article. Dr Crean and Prof Varcoe are the principal investigators of the EPSRC grants who contributed to the formulation of this article and scientific interpretation of the data.

\section{Conflicts of interest}

There are no conflicts to declare.

\section{Acknowledgements}

This research was funded by the UK's Engineering and Physical Sciences Research Council (EPSRC) with resources provided by grants EP/M005933/1, EP/M014371/1, and EP/M022749/1 (the latter providing the capital funding that allowed for the purchase of the Renishaw Raman microscope system). Renishaw are thanked for their technical assistance related to our familiarisation with the instrument. Wai Hin Lee thanks the University of Surrey for providing additional funding: the bulk of the results in this paper was from his undergraduate final year project. All data is freely available with no restrictions: details on how to access this data can be found at DOI: 10.15126/surreydata.00842458.

\section{References}

1 T. R. Dargaville, G. A. George, D. J. T. Hill and A. K. Whittaker, Prog. Polym. Sci., 2003, 28, 1355; M. M. Nasef, S. A. Gürsel, D. Karabelli and O. Güven, Prog. Polym. Sci., 2016, 63, 1.

2 M. M. Nasef, Chem. Rev., 2014, 114, 12278; L. Gubler, Adv. Energy Mater., 2014, 4, 201300827; A. Albert, T. Lochner, T. J. Schmidt and L. Gubler, ACS Appl. Mater. Interfaces, 2016, 8, 15297.

3 J. Pan, C. Chen, L. Zhuang and J. Lu, Acc. Chem. Res., 2012, 45, 473; J. R. Varcoe, P. Atanassov, D. R. Dekel, A. M. Herring, M. A. Hickner, P. A. Kohl, A. R. Kucernak, W. E. Mustain, K. Nijmeijer, K. Scott, T. Xu and L. Zhuang, Energy Environ. Sci., 2014, 7, 3135; K. D. Kreuer, Chem. Mater., 2014, 26, 361; M. A. Hickner, Interface, 2017, 26, 69; T. J. Omasta, L. Wang, X. Peng, C. A. Lewis, J. R. Varcoe and W. E. Mustain, J. Power Sources, 2017, DOI: 10.1016/ j.jpowsour.2017.05.006.

4 N. Walsby, M. Paronen, J. Juhanoja and F. Sundholm, J. Polym. Sci., Part A: Polym. Chem., 2000, 38, 1512; J. R. Varcoe, R. C. T. Slade, E. L. H. Yee, S. D. Poynton, D. J. Driscoll and D. C. Apperley, Chem. Mater., 2007, 19, 2686; O. I. Deavin, S. Murphy, A. L. Ong, S. D. Poynton, R. Zeng, H. Herman and J. R. Varcoe, Energy Environ. Sci., 2012, 5, 8584; B.-M. Ko, J.-Y. Sohn and J. Shin, Polymer, 2012, 53, 4652; M. Mamlouk, J. A. Horsfall, C. Williams and K. Scott, Int. J. Hydrogen Energy, 2012, 37, 11912; T. Zhou, R. Shao, S. Chen, X. He, J. Qiao and J. Zhang, J. Power Sources, 2015, 293, 946; R. Espiritu, M. Mamlouk and K. Scott, Int. J. Hydrogen Energy, 2016, 41, 1120; Y. Zhao, K. Yoshimura, H. Shishitani, S. Yamaguchi, H. Tanaka, S. Koizumi, N. Szekely, A. Radulescu, D. Richtere and Y. Maekawa, Soft Matter, 2016, 12, 1567.

5 J. R. Varcoe, R. C. T. Slade, G. L. Wright and Y. Chen, J. Phys. Chem. B, 2006, 110, 21041; S. F. Lu, J. Pan, A. B. Huang, L. Zhuang and J. T. Lu, Proc. Natl. Acad. Sci. U. S. A., 2008, 105, 20611; C. A. Hancock, A. Ong, P. R. Slater and J. R. Varcoe, J. Mater. Chem. A, 2014, 2, 3047; H. A. Miller, A. Lavacchi, F. Vizza, M. Marelli, F. Di Benedetto, F. D. I. Acapito, Y. Paska, M. Page and D. R. Dekel, Angew. Chem., Int. Ed., 2016, 55, 6004; H. A. Miller, F. Vizza, M. Marelli, A. Zadick, L. Dubau, M. Chatenet, S. Geiger, S. Cherevko, H. Doan, R. K. Pavlicek, S. Mukerjee and D. R. Dekel, Nano Energy, 2017, 33, 293-305; H. Wang and H. Abruña, J. Am. Chem. Soc., 2017, 139, 6807; L. Wang, J. J. Brink, Y. Liu, A. M. Herring, J. Ponce-González, D. K. Whelligan and J. R. Varcoe, Energy Environ. Sci., 2017, DOI: 10.1039/C7EE02053H.

6 J. Ponce-González, D. K. Whelligan, L. Q. Wang, R. BanceSoualhi, Y. Wang, Y. Q. Peng, H. Q. Peng, D. C. Apperley, H. N. Sarode, T. P. Pandey, A. G. Divekar, S. Seifert, A. M. Herring, L. Zhuang and J. R. Varcoe, Energy Environ. Sci., 2016, 9, 3724.

7 H.-P. Brack, H. G. Bührer, L. Bonorand and G. G. Scherer, J. Mater. Chem., 2000, 10, 1795; M. M. Nasef and E.-S. 
A. Hegazy, Prog. Polym. Sci., 2004, 29, 499; Y. Buchmüller, A. Wokaun and L. Gubler, Fuel cells, 2013, 13, 1177.

8 V. Sproll, T. J. Schmidt and L. Gubler, Polym. Int., 2016, 65, 174.

9 L. Q. Wang, E. Magliocca, E. L. Cunningham, W. E. Mustain, S. D. Poynton, R. Escudero-Cid, M. M. Nasef, J. PonceGonzález, R. Bance-Soualhi, R. C. T. Slade, D. K. Whelligan and J. R. Varcoe, Green Chem., 2017, 19, 831.

10 S. Holmberg, J. H. Näsman and F. Sundholm, Polym. Adv. Technol., 1998, 9, 121; L. I. Şanli and S. A. Gürsel, J. Appl. Polym. Sci., 2011, 120, 2313.

11 F. Cardona, G. A. George, D. J. T. Hill, F. Rousoul and J. Maeji, Macromolecules, 2002, 35, 355; F. Cardona, G. A. George, D. J. T. Hill and S. Perera, J. Polym. Sci., Part A: Polym. Chem., 2002, 40, 3191; H. Herman, R. C. T. Slade and J. R. Varcoe, J. Membr. Sci., 2003, 218, 147.

12 J. E. Katon, Vib. Spectrosc., 1994, 7, 201; A. Chaplin, I. Hamerton, H. Herman, A. K. Mudhar and S. J. Shaw, Polymer, 2000, 41, 3945; E. Widjaja and M. Garland, J. Raman Spectrosc., 2012, 43, 828; R. Zeng, J. Handsel, S. D. Poynton, A. J. Roberts, R. C. T. Slade, H. Herman, D. C. Apperley and J. R. Varcoe, Energy Environ. Sci., 2011, 4, 4925; D. M. Hillman, S. H. Stephens, S. D. Poynton, S. Murphy, A. Ong and J. R. Varcoe, J. Mater. Chem. A, 2013, 1, 1018; R. Zeis, Beilstein J. Nanotechnol., 2015, 6, 68; S. Mukherjee and A. Gowen, Anal. Chim. Acta, 2015, 895, 12; C. Cardell and I. Guerra, Trends Anal. Chem., 2016, 77,
156; T. R. Pozegic, J. V. Anguita, I. Hamerton, K. D. G. I. Jayawardena, J.-S. Chen, V. Stolojan, P. Ballocchi, R. Walsh and S. R. P. Silva, Sci. Rep., 2016, 6, 37334.

13 A. Zoubir, Raman Imaging: Techniques and Applications, Springer, Heidelberg NY (USA), 2012.

14 R. Espiritu, B. T. Golding, K. Scott and M. Mamlouk, J. Mater. Chem. A, 2017, 5, 1248; R. Espiritu, B. T. Golding, K. Scott and M. Mamlouk, J. Power Sources, 2017, DOI: 10.1016/ j.jpowsour.2017.07.074.

15 E. Smith and G. Dent, Modern Raman Spectroscopy: A practical Approach, Wiley, Hoboken NJ (USA), 2005.

16 R. L. McCreery, Raman Spectroscopy for Chemical Analysis, John Wiley \& Sons, New York (USA), 2005.

17 G. Galleja, A. Houdayer, S. Etienne-calas, D. Bourgogne, V. Flaud, G. Silly, S. Shibahara, A. Takahara, A. Jourdan, A. Hamwi and B. Ameduri, J. Polym. Sci., Part A: Polym. Chem., 2011, 49, 1517.

18 P. J. Larkin, Infrared and Raman spectroscopy: Principles and spectral interpretation, Elsevier, Amsterdam, 2011.

19 M. A. Vandiver, B. R. Caire, J. R. Carver, K. Waldrop, M. R. Hibbs, J. R. Varcoe, A. M. Herring and M. W. Liberatore, J. Electrochem. Soc., 2014, 161, H677; T. P. Pandey, A. M. Maes, H. N. Sarode, B. D Peters, S. Lavinia, K. Vezzu, Y. Yang, S. Poynton, J. R. Varcoe, S. Seifert, M. Liberatore, V. Di Noto and A. Herring, Phys. Chem. Chem. Phys., 2015, 17, 4367. 